\title{
UNBOXING THE DESIGN OF ENGLISH AS A SECOND LANGUAGE (ESL) LEARNING VIDEO GAME FOR INDIGENOUS LEARNERS: AN EMPATHIC DESIGN- BASED APPROACH
}

\author{
Mohd Syazwan Wan Mahzan1*, Nor Aziah Alias² and Izaham Shah Ismail² \\ ${ }^{1}$ Sekolah Menengah Kebangsaan Chiku 2, 18300 Gua Musang, Kelantan, Malaysia \\ ${ }^{2}$ Faculty of Education, Universiti Teknologi MARA, 42300 Bandar Puncak Alam, \\ Selangor, Malaysia \\ *Corresponding author: mohdsyazwanwm@gmail.com
}

Publication date: 23 December 2020

To cite this article: Mohd Syazwan Wan Mahzan, Nor Aziah Alias, \& Izaham Shah Ismail. (2020). Unboxing the design of English as a second language (ESL) learning video game for indigenous learners: An empathic design-based approach. Asia Pacific Journal of Educators and Education, 35(2), 39-56. https://doi.org/10.21315/apjee2020.35.2.3

To link to this article: https://doi.org/10.21315/apjee2020.35.2.3

\begin{abstract}
A learning application that can conjure meaningful learner experiences has always been the ultimate aim for any design and development initiative. Instructional designer longs for not only considerably rich inputs from expert members in design stage but those inputs ought to be sensitive to cognitive and emotional learner experiences, illuminating the core concept of empathic design which is deep reflection on how targeted learners impacted by the design would react when engaging with the proposed design solutions. This exploratory qualitative method study examined how subject matter experts empathised the cognitive and emotional experiences of the indigenous learners when they were designing a learning video game that aimed to heighten learning engagement in ESL classroom. A semi-structured interview with six experts was conducted. Once the proposed technology was ready for formative evaluation, one-to-one evaluation was conducted on three targeted learners to assess their usability experience. Thematic analysis was employed to analyse the interview verbatim transcriptions and one-to-one evaluation qualitative notes. The design findings indicate that the experts transformed the learner cognitive and emotional experiences for the learning video game design in the form of seven design principles and the evaluation findings show that there is a congruence between the effectiveness of those principles and the learner usability experience.
\end{abstract}

Keywords: Design principles, design solutions, cognitive experiences, emotional experiences, empathic design, indigenous learners 


\section{INTRODUCTION}

Mastering English as a second language (ESL) has been a tremendous challenge for many Malaysian learners (Noori, Shamary, \& Yuen, 2015). In the case of indigenous learners in Gua Musang, Kelantan, Malaysia, the situation is even worse as they experience extreme ESL deficiency due to their hard-to-engage and fusty attitudes (Ramle, Wan Hasmah, W. A. Amir, \& Asmawi, 2013). Majority of them enter secondary schooling years with ESL proficiency way below the expected level, making them struggle to cope with the prescribed curriculum at the secondary level (Ministry of Education Malaysia, 2013). When learners experience "imperfect" learning syndrome, an instructional intervention is necessary to resolve it. Such intervention could come in many forms such as teaching approach (Norwaliza, Ridzuan, Ramlee, Arasinah, \& Norhayati, 2017), specialised curriculum (Warid, 2013), programme (Intan Farahana, Rosseni, NorSyazwani, Analisa, \& Siti Zuraida, 2014), module (Siti Mariam \& Ruhizan, 2017) and digital material (Vanitha, Saedah, \& Norlidah, 2014).

Hence, reflecting on the indigenous learners' low English language proficiency level and the scarcity of learning materials to specifically support them in ESL learning, the researchers have launched a project to develop a Digital Game Based Learning (DGBL) material with the intention to make the passive indigenous learners engaged with ESL lessons and thus increase their proficiency level in the long run. Video game offers interactive gameplay, scaffolded challenges and multimodal elements (text, image, sound and multiplayer interaction) and its employment in learning context for learners of varying motivational and cognitive levels could engender a complex semiotic learning experience that leads to meaningful learning (Ikumi Hitosugi, Schmidt, \& Hayashi, 2014).

\section{BACKGROUND}

This article unfolds a part of the research initiative to design and develop an ESL learning video game for indigenous learners by focusing on its design stage. In this study, expert members in a design team actively engaged in continuous projection and reflection, aiming to help the researchers-cum-instructional designers determine the most desirable design solutions for the proposed video game package. McDonagh-Philp and Lebbon (2000) argue that cultural and emotional bonds greatly affect consumer's acceptance with any developed product. Design process demands experts in the design team to be able to empathise the targeted learners' needs and interests, exploring the emotional domain of a product design which influences user satisfaction. Aesthetic appeal, taste, usability, materials and 
sensory are among the possible design constructs to be construed from the design team experts. This article qualitatively reports on the exploration of cognitive and emotional needs of the targeted indigenous learners empathised by the design experts, which in turn would determine the learners' usability experiences.

\section{LITERATURE REVIEW}

\section{Empathic Design-based Approach in Product or Service Development}

Involvement of a design team consisting of diverse fields of expertise is a prerequisite for any design and development initiative (Dick, Carey, \& Carey, 2015). Let us say that a team is set to design a learning product for learners with visual impairments. The problem arises when it comes to coming up with sound design solutions since none of them happens to belong to the targeted user group. This anecdote reflects the arduous task contemplated by many design teams in order to make the most desirable design choices for the targeted users who are physically and emotionally different from themselves (Kouprie \& Visser, 2009). There has been an alarming concern regarding the inadequacy of ethics and values being embedded by engineers and designers in their designs. Sociotechnical emphasis sensitive to user needs is limited in design process, calling for a substantial reform in design methodology that should go beyond technical aspects (Gray, De Cresce El Debs, Exter, \& Krause, 2016). This idealism demands for an ethically centered design practice to produce design solutions that are responsive and effective to user needs.

In context of technology education scholarship, instructional technologists are challenged to make design solutions that are user friendly and effective to tackle the identified learning problems. Thus, complete detachment for selfpersonal ethics and technical capability is necessary to enable comprehensive understanding of real-world use from the lenses of targeted users (McDonaghPhilp \& Lebbon, 2000; Parrish, 2009; Vann, 2017). Such understanding requires empathic manifestation, be it for instructional technologists or expert members in design team, to enable them "predict" the lives and experiences of the end users when responding to the design solutions embedded in the developed technology. An empathically sensitive design increases the likelihood of the developed product to meet the users' needs in terms of ease of use and effectiveness. However, such emphatic role carried out by designers has not been explicitly explored (Vann, 2017). The present study was set to have a closer look on the demonstrations of such empathy by design team experts to comply with the targeted users' needs. The study outcomes could enrich the present literature regarding in what angles 
should the design team anticipate the user ability and needs and explore the possible fear, confusion, and frustration as a result of the design solutions being proposed.

\section{Empathy in Design Practice}

Kouprie and Visser (2009) proposes four phases of empathy in design process: discovery, immersion, connection, and detachment. These four phases serve as a framework that directs a designer through the life of the targeted users, roams around in it and finally steps out of the life upon having thorough understanding of the users' real-world contexts. The framework enables the designer to systematically tap his two empathic domains: affective and cognitive. The affective domain points to emotional reactions when listening to or observing the users' emotional states while the cognitive domain directs to the designer's ability to employ perspective taking, assuming the role of the users that he is targeting to. These two domains have been the substance of empathy mechanicsm in which perspective taking is often realised soon after the designer emotionally responds to the users' emotional state. Hence, undertaking separate discussions between these two is almost possible (Kouprie \& Visser, 2009). The researchers view such footing on how empathy mechanism works during the design process by likening it to a popular Malay proverb: Tak kenal, maka tak cinta (Without knowing [feeling the user's emotional state], there will be no love then [deep understanding via cognitive reasoning]).

\section{THE PURPOSE OF THE STUDY}

The primary purpose of this qualitative study was to explore how subject matter experts empathised the cognitive and emotional needs of the indigenous learners when they were designing a learning video game that aimed to heighten learning engagement in ESL classroom.

\section{RESEARCH QUESTIONS}

This study attempts to address the following questions:

- What are the design principles that inform the cognitive and emotional learner experiences?

- What are the leaners' reactions on the effectiveness of the embedded design principals in the learning video game prototype? 


\section{THE SIGNIFICANCE OF THE STUDY}

Studies concerning the development of video game for ESL learning have been very scarce due to its design and development complexity, together with the undeniably high production cost incurred. In Malaysia, game companies are more interested in developing digital games meant for fun purposes due to the market demand and handsome revenue generated from in-app advertisement. Hence, this study would forefront the learning video game segment in Malaysian education landscape, clinging mainly on the design principles retrieved via the employment of emphatic design-based approach. The outcomes of the study contribute to an understanding of the significance of design empathy during design stage: the imagination, knowledge negotiation and representation of the expert members to transfer future learner cognitive and emotional experiences into a set of design principles that serves as an important reference for the development of a meaningful learning video game.

\section{METHODOLOGY}

\section{Research Design}

This exploratory qualitative method study examines how subject matter experts empathised the cognitive and emotional experience of the indigenous learners when they were designing a learning video game that aimed to heighten learning engagement in ESL classroom. Once the learning video game was fully developed, learner evaluation was conducted to gauge the targeted learners' reactions on the usability of the embedded design principles in the prototype.

\section{Instrument}

The interview questions were semi-structured and self-designed based on relevant literature. Literature related to the theoretical stand points and lessons learned in learning via technology enhanced learning platform ranging from the employment of empathy in transdisciplinary technology education (Gray et al., 2016), learning engagement (Curry, 1991; Geisler et al., 2014), the influence of social and cultural contexts (Kaufman, 2004; Kessler, 2018), affective learning elements (Silver \& Perini, 2010) to responsive pedagogy for marginalised learners (Aronson \& Laughter, 2016), were used as a basis to construct the semi-structured interview questions and design possible probing questions. The one-to-one evaluation observation checklist form was also self-designed based on the final design solutions during the design stage. Both instruments were then revised by three 
experts in the fields of qualitative research methodology, ESL methodology and video game design and development. The instruments went through a validation process via pilot testing. After the pilot studies for both instruments were completed, the researchers reviewed the problematic items and revised them.

\section{Sample and Data Collection}

Semi-structured interview was conducted on four ESL teachers and two learning design experts and one-to-one evaluation of the developed learning prototype was carried out to three indigenous learners. For the semi-structured interview, the researchers applied purposive and snowball samplings to identify the potential expert informants. From the pool of expert informants, the ESL teachers chosen should have at least possess five years of experience teaching ESL to the targeted learners and the subject matter experts should possess expertise in the areas of ESL methodology, design-based research and technology enhanced learning. As for one-to-one evaluation, the learner informants should represent the range of ability of the population (Dick et al., 2015). Hence, the researchers selected one learner from low ability group, one average and another one from the top group.

\section{Data Analysis Procedures}

All the interviews were manually transcribed from the recording audios to verbatim transcripts. For one-to-one evaluation process, the process was recorded by the checklist provided and field notes. The researchers narrated the one-to-one evaluation process based on the notes written soon after each learner finished testing the learning prototype. Then, the raw qualitative data from both data collection methods were coded, themed, and refined by using a qualitative data management software named ATLAS.ti version 8.

\section{The Validity of the Results}

Throughout the coding and theming processes, the coded data were compared and discussed whether there were quotations, that belonged to the supposed codes and "homes", should be discarded for having no meanings or, another code or theme should be created (Braun \& Clarke, 2006; Piggot-Irvine \& Zornes, 2016). This constant comparison method helped the researchers slot in the quotations to the right codes and themes and reduce "unnecessary" quotations that do not weigh much to represent the codes and themes. At the same time, the ongoing interaction between the researchers serves as a member-checking tool to validate whether the results were accurate and parallel to the meanings intended by the informants. 


\section{The Reliability of the Coded Data}

Once the themes and the codes and the codes' quotations had been finalised, an external audit was conducted. To ensure coding reliability, two raters, experts in ESL teaching and instructional technology, independently rated their extent of agreement on the coded data. Cohen's kappa index was computed for interrater reliability. The Cohen's kappa coefficient $(\kappa)$ is 0.96 , indicating that the coded data has shown an almost perfect agreement (Cohen, 1960 and McHugh, 2012, as cited in Qian \& Clark, 2016). The value does not only serve as a piece of evidence of very minimal discrepancy between the researchers' and raters' judgement on the coded data, but it should be treated as a platform to refine and define further the coded data.

\section{RESULTS}

\section{From Semi-structured Interviews}

\section{Design Principle 1: Employ digital game-based learning to trigger learners' motivation towards active learning}

Nabila_teacher 2 believes that "the use of technology will attract [the indigenous learners] attention". This is evident when she claims that they will surround the teacher whenever they see instances of their teacher using smartphone. Some of the phone functions such as video and game applications attract the learners' interest. Another informant, Raziah_expert 1, is of the opinion that ESL teachers should consider exploiting game-based approach via the use of instructional technology because indigenous learners love any game-oriented and kinesthetics activities:

I was involved with the... preparing materials for Orang Asli (indigenous) learners three years back. So, basically what I got from fellow members in the course that Orang Asli (the indigenous), they prefer to have more games. Right? Game-based...they like to sing; they like to move. All the kinesthetics or whatever but not to look at the books all the time. (Raziah_expert 1) 


\section{Design Principle 2: Consider learners' present interests due to assimilation and accommodation process}

When asked about the present pop cultures experienced by indigenous learners due to the world without border offered by the Internet accessibility, Shanmuga expert 2 agrees that "they are into [Hindi and K-Pop songs] [in spite of being] so passive". This view inclines to suggest that there should be a consideration on pop culture elements which are outside their social boundary such as the use of modern weapons to kill enemies. Even though the weapon is not familiar in their context as compared to the traditional blowpipe, it is hypothesised that bringing in something beyond the norm into the game design can give more engaging effect towards their learning.

\section{Design Principle 3: Teacher sets up learning direction}

This theme examines the pedagogical aspects of teaching with the presence of technology. Two of the teacher informants describe teacher supposed roles in DGBL in which declaration of learning objectives and lesson recapitulation have to be executed explicitly:

Like I said before, before we play the game, I'll give them instruction- what they have to focus on, in other words, the objectives, for them to play the game and then we re-emphasize (recap the lesson) after they finish the game. (Izham_teacher 3)

True. That's the reflection part lah I would say. (Aimi_teacher 4)

In terms of the prospect for applying video game into ESL learning, they admit that it is, without doubt, can engage any learners, but teachers have to be professional so as not to treat the learning video game as a teacher substitute:

Yes, we can see, definitely... they will be interested. It is just the teachers have to be fair to the students, not having the games as a replacement for [them] not to teach. (Aimi_teacher 4)

Don't let the game dominate your lesson. You are the teacher. (Izham_teacher 3) 


\section{Design Principle 4: Learning should be a more dominant activity than playing}

An expert informant advises the researchers to address the learning aspect more than the playing part when designing and developing the proposed video game:

Oh, that one you have to ensure when you are designing the game. It is fun to play the game but when they play the game, they are also learning vocabulary. It is just like a crossword puzzle. When you create a crossword puzzle, you ask them to come up with words based on the crossword puzzle right? They are playing the game, at the same time, they are learning vocabulary. It is the same thing (with your project) so you need to balance it. You can't have game $60 \%$ and learning $40 \%$. It should be $40 \%$ of playing and $60 \%$ learning. (Shanmuga_expert 2)

\section{Design Principle 5: Focus on cognitive engagement rather than the feeling of fun}

The set language tasks in the video game should focus on language learning, and the fun part is used as a means to fulfill the language tasks. Izham_teacher 3 argues that the entire video game ought to be mainly about language learning and the fun elements characterised by video game should be treated as a supplement to engage learners in learning. However, Aimi_teacher 4 believes that teachers play a crucial role for the success of instruction:

It depends on the teachers, how the teachers manage the game. Meaning that it is either to focus on the task or the teacher says, "just play the game" (It is all about mind setting). For example, the teacher needs to give a clear instruction, telling that they need to complete the task instead of merely playing the game for fun. (Aimi_teacher 4)

Izham_teacher 3 duly agrees on the point put forth by Aimi_teacher 4 . He states that "it is a matter of how [teachers] are going to balance out" between the learning and fun part so that the learning outcomes can be seen as the focus rather than making the learners overwhelmed too much with the fun part of gaming. This discussion has addressed the importance of prioritising the learning aspects into the proposed video game. 


\section{Design Principle 6: Reset learning for another learning to take place}

When asked about the use of violent elements, rewards and punishments, mixed reactions were received from the teacher and expert informants. Nabila_teacher 2 feels that violent elements are effective to engage learners learning in video game platform but since the aim of the proposed video game is for school goers, the violent part should not be too extreme. Narita_teacher 1 argues that the element of goal setting to be achieved in video game is intriguing, making the learners overwhelmed with the virtual exploration being offered by the platform. The following entry reflects the aforementioned arguments made by these two teacher informants:

Yes, I do agree but the gameplay should not be too extreme. If we do video game with no fight scenes whatsoever, it will be boring for them. They might play it for one or two times but that is all. Without the violent element, it is going to kill their enthusiasm to play. (Nabila_teacher 2)

And they should be a goal to achieve (for any game). If there is not, why do you play the game in the first place right? (she laughed) (Narita_teacher 1)

Izham teacher 3 and Aimi teacher 4 also think along the same line. For Aimi_teacher 4, violent theme seems to complement the game mission in video game in which it requires "[one's] eagerness to kill the main villain (the goal mission for the prime game), the boss, the supreme boss" for engagement purpose:

Because what we call the eagerness to kill the main villain (the goal mission for the prime game), the boss, the supreme boss, that's why we are heading to that direction. (Aimi_teacher 4)

Somehow that thing, we don't mean to actually promote violence. Violence in bracket (in another context) will make the players feel satisfied. (Izham_teacher 3)

\section{Design Principle 7: Allow learners to reflect on learning}

Aimi teacher 4 wishes to have a video game that could consolidate previous learning and it is recommended to have a score summary so that learners can review what they have performed throughout their gaming session. Coming up with a score summary for each task or mission completion is one of the must-have 
features in video game. However, according to Nasrul Radhi, a game developer, he contends that having shown too much info on a summary board would be a waste of time because the players most of the time ignore its presence. They are more interested in continuing their journey for the next mission rather than spending their time reading the scores (Personal communication, 15 October 2018). He suggested the researchers to consider the employment of immediate feedback in the form of rewards and punishments during the gameplay.

\section{From One-to-one Evaluation}

Table 1 shows the demographic backgrounds of three learner informants.

Table 1. Demographic backgrounds of the learner informants

\begin{tabular}{lccc}
\hline Pseudonym & Gender & Proficiency level & Attitude towards digital gaming \\
\hline Sara & $\mathrm{F}$ & Top & Medium \\
Rico & $\mathrm{M}$ & Average & High \\
Refon & $\mathrm{M}$ & Low & Low \\
\hline
\end{tabular}

\section{Sara}

She plays a variety of simple games on her mobile phone and school computer. She required about 54 minutes to playtest the prototype. She completed all the game scenes in easy mode with minimal support from the researchers and five-game overs in total. Informant 1_Sara said that she felt [really enjoyed] "best sangat" playing the prototype. She mentioned that the vocabularies tested were common but fulfilling the language tasks was challenging as she got to act 'quickly', implying to the uphill task of solving the language task while overcoming the game challenges.

(All the words are common but the game is difficult because I've to be quick).

Semua [kosa kata] tu biasa cikgu tapi susoh sebab kena cepat. (Informant 1_Sara)

\section{Rico}

He is familiar with complex games like Player Unknown's Battlegrounds (PUBG), Clash of Clans $(\mathrm{CoC})$ and Counter Strike. He clocked 45 minutes to finish the playtest and completed all the game scenes in easy mode with much support from the researchers particularly on the language tasks. As for the game challenges, he 
was a good game player as he was able to "nullify" the threats by comfortably moving around the game environment while depleting the health of the enemies. Informant 2_Rico claimed that even though the language tasks were difficult, he felt committed to complete them because the game was fun, different from what he used to have with his teachers:

(Difficult but fun. Could try many times. There is no game like this in class).

Susah tapi seronok. Boleh cuba banyak kali. Kalau dalam kelas, takde game macam ni cikgu. (Informant 2_Rico)

\section{Refon}

$\mathrm{He}$ is not into mobile or computer games as he spends his time with mobile phone mostly on watching football video clips and listening to Dikir Barat (traditional chants) songs. He took 1 hour and 10 minutes to playtest the developed learning video game. He completed all the game scenes in easy mode with much support from the researchers on both, the gameplays and language tasks. $\mathrm{He}$ needed the support as he was not familiar with the gameplays due to his limited interest in playing digital games. When asked about his gaming experience, Informant 3_Refon revealed that the challenges were fun but completing the language tasks was tough:

(Quite difficult but I wish to play it again. This time, it would be on my own).

Susah jugak tapi nak main lagi cikgu sendiri [pula lepas ini]. (Informant 3_Refon)

However, the researchers could see his unwavering perseverance and deep engagement to explore the game from one scene to another, albeit the need to scaffold his game progress from time to time due to his limited language proficiency.

\section{Summary of the One-to-one Evaluation in terms of the Effectiveness of the Employed Design Strategies}

Table 2 shows the overall outcomes of one-to-one evaluation of the developed video game prototype. 
Table 2. Overall outcomes of the one-to-one evaluation of the developed video game prototype

\begin{tabular}{|c|c|c|c|c|c|c|}
\hline \multirow{3}{*}{ Design Strategies } & \multicolumn{2}{|c|}{ Informant 1_Sara } & \multicolumn{2}{|c|}{ Informant 2_Rico } & \multicolumn{2}{|c|}{ Informant 3_Refon } \\
\hline & Effective & $\begin{array}{c}\text { Not } \\
\text { effective }\end{array}$ & Effective & $\begin{array}{c}\text { Not } \\
\text { effective }\end{array}$ & Effective & $\begin{array}{c}\text { Not } \\
\text { effective }\end{array}$ \\
\hline & 1 & -1 & 1 & -1 & 1 & -1 \\
\hline Control scheme & / & & l & & / & \\
\hline Game instruction & & l & l & & & I \\
\hline Game buttons & / & & / & & / & \\
\hline Game challenges & l & & I & & I & \\
\hline Vocabulary language tasks & / & & / & & / & \\
\hline Rewards and penalties & & / & / & & 1 & \\
\hline Space control/manipulation & l & & I & & & l \\
\hline Language use & & / & & l & & / \\
\hline Sound impact & & I & & l & & l \\
\hline Visual effects & & l & & l & & l \\
\hline Game storyline & I & & / & & I & \\
\hline Game missions/objectives & / & & / & & I & \\
\hline Character depiction & / & & / & & l & \\
\hline
\end{tabular}

\section{DISCUSSION}

This exploratory study illuminates the prevalent role of expert members in design team to wear the hat of designer as user. It is a perspective-taking competency to be in the shoes of the targeted users that the learning product is meant for. Throughout the design process, it could be concluded that the expert members' reactions were slated to the design of how the indigenous learners would be impacted, should the design solutions be embedded in the learning prototype.

The ESL teachers and subject matter experts opted to project and emote future goals and visions to imagine the possible cognitive and emotional experiences of the indigenous learners in response to particular design principles. For instance, some of the teacher informants outlined the nature of DGBL materials that they hoped for - the learning part should be more dominant that the playing part - as they were aware with the overwhelming effects that a digital game could possibly impact their learners. Such opinion was the manifestation of their personal detachment to accurately project possible behavioral outcomes of the targeted learners (Vann, 2017). 
Kouprie and Visser (2009) argue that design team members are inclined to make design solutions which are emotionally bound to the targeted learners. Such view is congruent with one of the findings in the study in which one expert informant reveals the fact how Hindi and K-Pop songs have surprisingly become a craze among the indigenous learners even though majority of them are naturally reticent. Hence, the researchers' initial plan to only deliberate on culturally relevant design solutions has to be reconsidered since introducing elements beyond norm could enhance the learners' engaging effect towards learning.

The aforementioned instances are the testament of self-dialogic process that allows the design team members to propose innovative solutions for any illstructured design problems and thus give instructional designers an ample space to critically reflect and refine further the readily stable well-defined solutions (Cross, 2006). Together with instructional designers, design team members are just like engineers in which their ultimate aim is not only to design a functional product but the product should be appealing, emotionally and cognitively (Smith \& Ragan, 2005).

However, in spite of the core need to satisfy the different needs of the learners, and, pedagogical and technical requirements based on the multidisciplinary perspectives of the expert members, the researchers, who took the role as the instructional designers of the project, were 'shoved' to make necessary adjustments on the proposed design principles and strategies. Potential problems of the proposed solutions ought to be professionally weighed in and sensitised before development stage kicks off. Dick et al. (2015) avow this view by arguing about the flexibility of not complying to all the suggestions given by those specialists as instructional designers have better credibility to empathically forecast the nuances of the user needs before formative evaluation takes place.

It is duly noted here that, the learning video game prototype was in a refinement phase as the one-to-one evaluation phase falls under formative evaluation stage. In spite of being judged ineffective for some design strategies, i.e., game instructions, use of rewards and penalties, language use, sound impact and visual effects, a tune-up is only needed on them, not to the point of replacing them with another set of design strategies. Other than that, learner differences in terms of cognitive and affective levels affect the game flow, thus informing learners' ease of use and usefulness (Hoffman \& Nadelson, 2010). In one-to-one evaluation, the researchers discovered that the observed performance indications and reactions to the ESL learning video game content had been highly dependent on their past gaming experience and language proficiency level. 


\section{CONCLUSION}

Designing technology-oriented instruction requires one to be the archetypes of artist, problem solver and performer. An instructional designer as artist is typically a person who could develop a streamline of effective solutions for the identified learning problems, deal critically with ill-defined problems and turn a basic design architecture into a unique one. A designer embracing problem solving attitude systematically plans realistic yet effective procedures, fixes the root cause of the problem, not merely its symptom, and efficiently does what it takes to solve any arising design problem within the milestone schedule in spite of being edged by limited resources. An instructional designer also ought to have the perspective of a performer in which learner satisfaction becomes the central focus as learning absorption is better when learners are having fun.

These competencies are regarded as the essence of empathic design-based approach that intends to imagine and reflect, as accurately as possible, the extent of targeted learner ease of use and usefulness of the proposed design solutions. Such projection and reflection are not a one-off process as instructional design necessitates designers to indulge in continuous empathic negotiation within any instructional design models chosen. Existing instructional design or technological models have been criticized for only being helpful in assisting novice instructional designers learn the successfully proven patterns and approaches with limited emphasis on their design processes (Gibbons, Boling, \& Smith, 2014; Richey, Klien, \& Tracey, 2011). Hence, this study has bridged that gap by adding certain depth and breadth in instructional design literature about design process from the perspective of empathic design since producing a successful design often becomes top of wish list for all designers.

\section{Lessons Learned from the Study}

This study does not intend to illuminate the absolute effectiveness of employing empathic design-based approach in design process but rather shares lessons learned from a highly contextualised case study of such employment in the context of ESL learning video game design and development meant for vulnerable group. Hence, the researchers wish to highlight the following lessons that could be learned from the study:

1. Design actions taking place in present and future time perspectives form a vital source of practical solutions worth to be considered for the decision of overall design solutions before developing any instructional technology product. These forms of empathic forecasting open a window to expert 
members and instructional designer to be in the shoes of learners, making a critical attempt to reflect learners' present needs and interests and empathically project more pedagogically responsive design in compliance with their future cognitive and emotional experiences.

2. Novice instructional designers who lead a design and development project should be aware of the different instructional designer archetypes undertaken by expert members in design team. Besides that, those novice, acting as the lead researchers, ought to employ the same roles by critically reflecting on the proposed design solutions and eventually making final design decisions based on myriad perspectives such as the process of design construction, the practicality of the proposed design and possible tune-up for well-defined design problems. The ability to interpret all these perspective taking processes as accurate as possible would benefit young designers in their future design and development endeavors.

\section{ACKNOWLEDGEMENTS}

The authors are indebted to the Institute of Research Management and Innovation (IRMI), Universiti Teknologi MARA, Selangor, Malaysia for the research, authorship and publication of this article under Grant No. 600-IRMI 5/3/GIP (080/2018).

\section{REFERENCES}

Aronson, B., \& Laughter, J. (2016). The theory and practice of culturally relevant education: A synthesis of research across content areas. Review of Educational Research, 86(1), 163-206. https://doi.org/10.3102/0034654315582066

Braun, V., \& Clarke, V. (2006). Using thematic analysis in psychology. Qualitative Research in Psychology, 3(1), 77-101. https://doi.org/10.1111/j.1460-2466 .1978.tb01621.x

Cross, N. (2006). Engineering design methods: Strategies for product design. Chicester, New York, Weinheim, Brisbane, Singapore, Toronto: John Wiley \& Sons, Ltd.

Curry, L. (1991). Patterns of learning style across selected medical specialties. Educational Psychology, 11(247), 77.

Dick, W., Carey, L., \& Carey, J. O. (2015). The systematic design of instruction ( $8^{\text {th }}$ Edition). PEARSON.

Geisler, C., Grice, R., Bennett, A., Fernheimer, J. W., Krull, R., Search, P., ... Hart-Davidson, B. (2014). Designing for user engagement on the Web: 10 basic principles. New York and London: Routledge. https://doi.org/10.4324/9780203526224 
Gibbons, A. S., Boling, E., \& Smith, K. M. (2014). Instructional design models. In J. M. Spector et al. (Eds.), Handbook of research on educational communications and technology (pp. 607-615). New York: Springer.

Gray, C. M., De Cresce El Debs, L., Exter, M., \& Krause, T. S. (2016). Instructional strategies for incorporating empathy in transdisciplinary technology education. ASEE Annual Conference and Exposition, Conference Proceedings, June. https://doi.org/10.18260/p.25746

Hoffman, B., \& Nadelson, L. (2010). Motivational engagement and video gaming: A mixed methods study. Educational Technology Research and Development, 58(3), 245-270. https://doi.org/10.1007/s11423-009-9134-9

Ikumi Hitosugi, C., Schmidt, M., \& Hayashi, K. (2014). Digital game-based learning (DGBL) in the L2 classroom: The impact of the UN's off-the-shelf videogame, food force, on learner affect and vocabulary retention. CALICO Journal, 31(1), 19-39. https://doi.org/10.11139/cj.31.1.19-39

Intan Farahana Kamsin, Rosseni Din, NorSyazwani Mat Salleh, Analisa Hamdan, \& Siti Zuraida Abdul Manaf. (2014). Making behaviour change among Orang Asli students through ICT literacy program. ICSSR E-Journal of the Social Science Research, 1(2), 27-34.

Kaufman, D. (2004). Constructivist issues in language learning and teaching. Annual Review of Applied Linguistics, 24, 303-319. https://doi.org/10.1017/S0267190504000121

Kessler, G. (2018). Technology and the future of language teaching. Foreign Language Annals, 51(1), 205-218. https://doi.org/10.1111/flan.12318

Kouprie, M., \& Visser, F. S. (2009). A framework for empathy in design: Stepping into and out of the user's life. Journal of Engineering Design, 20(5), 437-448.

McDonagh-Philp, D., \& Lebbon, C. (2000). The emotional domain in product design. The Design Journal, 3(1), 31-43. https://doi.org/10.2752/146069200789393562

Ministry of Education Malaysia. (2013). Preliminary report: Malaysia education blueprint 2013-2025. (Vol. 27). Putrajaya: Author. https://doi.org/10.1016/j.tate .2010 .08 .007

Noori, M. A. J. H. Al, Shamary, I. H. K., \& Yuen, C. K. (2015). A review on the inconsistent English language policy in teaching and learning at secondary school level in the Malaysian education system. International Journal of Education and Research, 3(12), 245-260.

Norwaliza Abdul Wahab, Ridzuan Jaafar, Ramlee Mustapha, Arasinah Kamis, \& Norhayati Mohd Affandi. (2017). The effectiveness of likes method in improving reading skills of Orang Asli students. Asian Social Science, 13(6), 74. https://doi.org/10.5539/ass.v13n6p74

Parrish, P. E. (2009). Aesthetic principles for instructional design. Educational Technology Research and Development, 57(4), 511-528. https://doi.org/10.1007/s11423 -007-9060-7

Piggot-Irvine, E., \& Zornes, D. (2016). Developing a framework for research evaluation in complex contexts such as action research. SAGE Open, 6(3), 1-15. https://doi.org/10.1177/2158244016663800 
Qian, M., \& Clark, K. R. (2016). Game-based learning and 21st century skills: A review of recent research. Computers in Human Behavior, 63(May), 50-58. https://doi.org/10.1016/j.chb.2016.05.023

Ramle Abdullah, Wan Hasmah Wan Mamat, W. A. Amir Zal, \& Asmawi Mohammad Ibrahim. (2013). Teaching and learning problems of the orang asli education: Students' perspective. Asian Social Science, 9(12), 118-124. https://doi.org/ 10.5539/ass.v9n12p118

Richey, R., Klien, J., \& Tracey, M. (2011). The instructional design knowledge base: Theory, research, and practice. New York and London: Routledge.

Silver, H. F., \& Perini, M. J. (2010). The eight Cs of engagement: How learning styles and instructional design increase student commitment to learning. In R. Marzano (Ed.), Excellence in teaching (pp. 319-344). Bloomington, IN: Solution Tree.

Siti Mariam Dasman, \& Ruhizan Mohammad Yasin. (2017). Design of environmental education module towards the needs of aboriginal community learning. In AIP Proceedings of the International Conference on Education, Mathematics and Science 2016 (ICEMS2016) (Vol. 080002-1). AIP Publishing. https://doi.org/10.1063/1.4983914

Smith, P., \& Ragan, T. (2005). Instructional design (3rd ed.). Danvers, MA: John Wiley \& Sons, Inc.

Vanitha Thanabalan, Saedah Siraj, \& Norlidah Alias. (2014). Development of a responsive literacy pedagogy incorporating technology for the indigenous learners in Malaysia. TOJET: The Turkish Online Journal of Educational Technology, 13(2), 44-53.

Vann, L. S. (2017). Demonstrating empathy: A phenomenological study of instructional designers making instructional strategy decisions for adult learners. International Journal of Teaching and Learning in Higher Education, 29(2), 233-244. Retrieved from http://www.isetl.org/ijtlhe/

Warid Mihat. (2013). The English Language curriculum in Malaysian indigenous primary classrooms: The reality and the ideal. 3L. The Southeast Asian Journal of English Language Studies, 21(3), 1-12. 